\title{
CONCEPCÕES DE CRIATIVIDADE: MOVIMENTOS EM UM CONTEXTO DE ESCOLARIZAÇÃO FORMAL
}

\author{
Andréa Vieira Zanella* \\ Sílvia Zanatta Da Ros \\ Alice Casanova dos Reis \\ Kelly Bedin França
}

\begin{abstract}
RESUMO. Neste artigo são analisadas as concepções de criatividade de 11 acadêmicos de Psicologia da Universidade Federal de Santa Catarina (UFSC), regularmente matriculados na disciplina Psicologia da Criatividade no primeiro semestre de 2001. A psicologia histórico-cultural foi escolhida como referencial teórico e metodológico. Os dados foram coletados através de entrevistas semi-estruturadas, realizadas no início e ao final do semestre letivo. Como resultado constatou-se a permanência das concepções de criatividade por parte de 3 sujeitos. Nos demais se constatou mudanças, com destaque para a superação de uma concepção inatista de criatividade. De modo geral, destacou-se a complexificação nas respostas apresentadas pelos entrevistados, revelando que o processo vivido possibilitou ressignificações das concepções analisadas.
\end{abstract}

Palavras-chave: criatividade; ensinar e aprender; constituição do sujeito.

\section{INVESTIGATING CREATIVITY CONCEPTIONS: MOVEMENTS IN AN EDUCATIONAL CONTEXT}

\begin{abstract}
In this article, the creativity conception of 11 psychology students, enrolled in Creativity Psychology class in the first semester of 2001 was analyzed. Data was collected through interviews, done at the beginning and ending of the academic semester. The results suggested that the creativity conceptions of 3 students has remained. In the others, changes were evidenced, prevailing the overcoming of an innate creativity conception. In general, the complexity in the answers revealed that with the process was possible to built news significations of the analyzed conceptions.
\end{abstract}

Key words: creativity, teaching, learning, subjectivity.

\section{INTRODUÇÃO}

O presente trabalho apresenta alguns resultados do projeto de pesquisa "Criatividade e Constituição do Sujeito em Contexto de Ensinar e Aprender: uma análise à luz da Psicologia Histórico-Cultural". Focalizam-se aqui as concepções de criatividade de 11 acadêmicos regularmente matriculados em uma disciplina optativa ${ }^{1}$ do curso de graduação em psicologia da Universidade Federal de Santa Catarina (UFSC), com ênfase na gênese do criar e possíveis modificações decorrentes de reflexões teóricas e vivências estéticas em um contexto de escolarização formal. Destaca-se assim a dupla dimensão da atividade criadora na referida disciplina: além de se constituir como constructo teórico a ser discutido pelos sujeitos em relação, o criar configurou as

\footnotetext{
Doutora em da Psicologia da Educação pela PUC-SP, professora do Departamento e do Programa de Pós-Graduação em Psicologia da UFSC, bolsista em produtividade do CNPq.

Endereço para correspondência: Psicologia, CFH, Universidade Federal de Santa Catarina (UFSC), Campus Trindade , CEP 88010-970, Florianópolis-SC. E-mail: azanella@cfh.ufsc.br

\# Doutora em da Psicologia da Educação pela PUC-SP, professora do Departamento de Estudos Especializados e Programa de Pós-Graduação em Educação da UFSC.E-mail: ros@ @fh.ufsc.br

II Acadêmica do curso de Psicologia da UFSC, bolsista de Iniciação Científica pelo programa DAP/UFSC. E-mail: alicecasanova@hotmail.com

x Acadêmica do curso de Psicologia da UFSC, bolsista de Iniciação Científica pelo CNPq. E-mail: pradojb@matrix.com..br

1 A disciplina em questão intitulava-se "Psicologia da Criatividade" e era oferecida aos acadêmicos de Psicologia a partir da $5^{\mathrm{a}}$ fase do curso, como opção para integralização de créditos optativos.
} 
atividades propostas a esses mesmos sujeitos, empreendidas no contexto de sala de aula.

Como aporte teórico-metodológico adotado tanto para as discussões sobre a temática criatividade quanto para a análise dos resultados aqui apresentados, optouse pela Psicologia Histórico-Cultural, fundamentalmente as contribuições de Lev S. Vygotski $^{2}$ e alguns de seus interlocutores. Essa perspectiva teórica concebe o processo de constituição do sujeito como inexoravelmente social, sendo a atividade criadora necessariamente mediada e constituída em contextos histórico, social e cultural.

De acordo com a psicologia de Vygotski (1990), a possibilidade de criar constitui-se, no desenvolvimento humano, em consonância com a constituição da consciência, e revela uma relação entre o homem e seu entorno que supera a simples reprodução do que já é conhecido. O uso de ferramentas psicológicas ${ }^{3}$, ou seja, de produções simbólicas que permitem conhecer e comunicar a realidade, possibilita o desenvolvimento de processos psicológicos superiores ${ }^{4}$ e da consciência, a qual se relaciona, desse modo, à atividade criadora.

O contato com padrões estéticos, modos de trabalhar matérias-primas, enfim, a apropriação do que há disponível socialmente revela também que em toda criação individual há sempre um coeficiente social (Vygotski, 1990). Nesse sentido, o sujeito é capaz de criar justamente a partir dos/nos encontros que estabelece com outros sujeitos, encontros esses

2 A diferença entre o alfabeto cirílico, utilizado na Rússia, e o ocidental, impede uma transcrição precisa entre idiomas, o que justifica as variações da grafia do nome de Vygotski. No decorrer do texto optamos pela utilização da grafia com as letras " $y$ " após a consoante inicial e " $\mathrm{i}$ " no final, visto que esta se aproxima foneticamente do nome em russo. No entanto, mantivemos, no caso de citações e referências bibliográficas, os diferentes modos de escrever o nome de Vygotski, respeitando as escolhas dos autores.

3 "As ferramentas psicológicas são formações artificiais; são sociais por sua natureza, e não dispositivos orgânicos ou individuais; seu objetivo é governar os processos de atuação, alheia ou própria, de mesmo modo que está dirigida a técnica a governar os processos da natureza. Como exemplos de ferramentas psicológicas e de seus sistemas complexos podem servir: o idioma, as distintas formas de numeração e cálculo; os recursos mnemotécnicos; a simbologia algébrica; as obras de arte; a escrita; os esquemas; os diagramas, os mapas, os desenhos; todas as formas possíveis de signos convencionais, etc" (Vygotski, 1987, p.182)

4 Vygotski utiliza o conceito de processo psicológico superior para se referir às atividades psicológicas semioticamente mediadas, como a linguagem, o pensamento, a memória deliberada. mediatizados pelas possibilidades e limites das relações sociais em cada momento histórico.

De acordo com Vygotski (1990), a atividade criadora se realiza de forma circular e envolve diversos processos psicológicos superiores, entre os quais se destacam: 1) a percepção de determinados aspectos da realidade e a acumulação, pela memória, dos elementos mais significativos para o sujeito dentre a totalidade dos aspectos percebidos; 2) a reelaboração desses elementos através da fantasia, processo no qual estão presentes tanto a cognição quanto a vontade e o afeto, cuja influência nas combinações da imaginação se dá através da atração exercida pelo signo emocional comum $^{5}$; e, finalmente, 3 ) a objetivação do produto da imaginação, a qual, ao materializar-se na realidade, traz consigo uma nova força, que se distingue por seu poder transformador frente à realidade da qual partiu.

Logo, ao ser objetivada, a criação materializa projetos imaginativos de seu produtor. Desse modo, a psicologia histórico-cultural parte do pressuposto que a imaginação, ao condensar fragmentos diversos oriundos da vivência social de cada ser humano, permite projetar o que ainda não existia concretamente, constituindo-se assim como condição para toda e qualquer transformação em diferentes esferas da realidade.

Nesta perspectiva, portanto, não se pode definir a criatividade como um dom, como algo inerente ao sujeito, pois a possibilidade de criar resulta de um aprendizado que pode ocorrer ao longo da história de cada pessoa. Esta, por sua vez, está irremediavelmente ligada ao contexto histórico e, portanto, às condições concretas de que dispõe o sujeito para atuar e conhecer, já que a atividade caracteristicamente humana é semioticamente mediada, enfim, cultural.

\section{MÉTODO}

Os resultados que serão aqui apresentados consistem em um recorte de uma investigação maior que articula três eixos de análise: constituição do sujeito, atividade criadora e contextos de escolarização formal. Entende-se que essa articulação é possível na

5 O signo emocional é, segundo Vygotski, responsável pelo caráter inusitado das imagens produzidas pela atividade da fantasia, pois tais imagens se combinam não segundo uma lógica exterior, mas porque possuem um tom afetivo comum: "As imagens da fantasia funcionam também como linguagem interior aos nossos sentimentos, selecionando determinados elementos da realidade e combinando-os de tal maneira que respondam ao nosso estado de ânimo interior e não à lógica exterior dessas próprias imagens" (Vygotski, 1990, p.21 - tradução livre das autoras). 
medida em que se parte do pressuposto que a constituição do sujeito resulta do movimento de apropriação das significações nas atividades que empreende (Pino, 1995). Em se tratando de atividades criadoras, é possível afirmar que a obra ao mesmo tempo que modifica a realidade, imprimindo-lhe novas significações, igualmente (trans)forma o sujeito que a produziu. Um artefato artístico, por exemplo, contém em si, condensadas num amálgama complexo, além da objetivação da atividade daquele que o concretiza, características do meio social em que este se insere e que o constitui enquanto sujeito singular.

A atividade criadora em contextos de escolarização formal requer ser reconhecida tanto pelo seu autor como pelos outros como produtora de algo estético. Além disto pressupõe reflexões sobre o próprio processo de criação, permitindo explicá-lo em sua gênese, bem como em suas características.

Foi com a intenção de explicitar as concepções de criatividade de acadêmicos de psicologia e suas possíveis modificações que optamos por analisar a fala de alguns sujeitos sobre criatividade. Para tanto, foi escolhida como instrumento para a coleta de informações a entrevista semi-estruturada (Triviños, 1987), realizada em dois momentos: nas duas primeiras semanas do semestre letivo em que a disciplina optativa "Psicologia da Criatividade" foi oferecida e após o seu encerramento, quando os acadêmicos foram novamente entrevistados. Ainda que na disciplina estivessem inscritos 16 alunos, apenas 11 deles concordaram em participar das entrevistas. É preciso destacar, porém, que não foi possível efetivar a última entrevista com um dos sujeitos (Sujeito 7), porquanto o mesmo não compareceu aos vários encontros que foram conjuntamente acordados. Desse modo, as análises dos dados iniciais incidiram sobre a fala de 11 acadêmicos e os finais de 10 sujeitos.

As entrevistas foram previamente agendadas e realizadas individualmente, no campus universitário, em locais variados à escolha dos sujeitos. Tiveram uma duração média de 30 minutos e foram registradas com o auxílio de um microgravador, sendo posteriormente transcritas.

O material obtido foi trabalhado de acordo com a análise de conteúdos, técnica que permite protagonizar os sujeitos da pesquisa ao assumirem o lugar de produtores do conhecimento. Franco (1994, p.164) afirma que é importante reconhecer "....a utilização da análise de conteúdo como procedimento de pesquisa, dentro de uma abordagem metodológica crítica e epistemologicamente apoiada numa concepção de ciência que reconhece o papel ativo do sujeito na produção de conhecimento".
Nesse sentido, as falas dos sujeitos obtidas através das entrevistas foram consideradas como mensagens que expressavam concepções de criatividade e que explicitavam determinados pressupostos teóricos acerca da gênese do criar e das características do mesmo. Foram destacadas como indicativos desses pressupostos palavras específicas que remetiam à temática e expressavam, de certo modo, filiações a perspectivas psicológicas específicas.

A construção de categorias de análise foi realizada, portanto, a posteriori, o que significa dizer que estas emergiram das falas dos sujeitos a partir do que se considerou indicador das concepções de criatividade, a saber, palavras que remetiam à sua gênese. Em razão dessa opção metodológica, necessário se fez voltar várias vezes às entrevistas e, com o suporte do referencial teórico, identificar esses elementos indicadores das referidas concepções.

É necessário ainda esclarecer que as categorias elencadas na primeira etapa foram mantidas quando da análise das entrevistas finais. Isto em razão do objetivo delineado nesse momento da pesquisa, qual seja, identificar possíveis modificações na concepção de criatividade de acadêmicos de psicologia decorrentes de reflexões teóricas e vivências estéticas em um contexto de escolarização formal. Por um lado, tal opção metodológica permitiu identificar o movimento de permanência e mudança nas concepções dos sujeitos entrevistados; por outro lado, se fez necessário introduzir uma outra categoria de análise das respostas, em função da incidência pela qual se manifestou.

\section{RESULTADOS}

As entrevistas foram realizadas a partir de um roteiro com várias perguntas, todas relacionadas à proposta da pesquisa como um todo. Quanto ao recorte que aqui apresentaremos, as análises centraram-se inicialmente em uma questão especifica: "O que é criatividade?".

$\mathrm{Na}$ entrevista inicial, obtiveram-se respostas que foram categorizadas da seguinte forma: 1) "Criatividade como potencial", com 5 respostas; 2) "Criatividade como construída", com 4 respostas; e 3) as duas últimas respostas foram categorizadas como "todos são criativos".

Entendemos que as categorias de respostas 1 e 3 indicam uma mesma perspectiva, visto que veiculam uma concepção de algo dado, de uma natureza humana que antecede as experiências sociais. Em outras palavras, entendemos que as respostas de 7 sujeitos caracterizam uma concepção inatista de 
criatividade, considerando-a como potencial a ser desenvolvido e, nesse sentido, um dado a priori (categoria 1), ou algo que todos possuem naturalmente (categoria 3). Ilustramos essas categorias de respostas nas falas que seguem:

\begin{abstract}
"Mas é uma coisa de deixar a pessoa livre, assim bem essa coisa de deixar o potencial criativo, o ato de criar (...) a criatividade tem que ser uma coisa espontânea, sabe?" (Sujeito 8 - categoria de resposta 1 ).

"Em criança eu acho que é mais fácil porque elas já são naturalmente criativas(...) todo mundo é criativo de certa forma..." ( Sujeito 1 - categoria de resposta 3 ).
\end{abstract}

É corrente no senso comum a idéia de que a criatividade é algo que nasce com o indivíduo, e de que os artistas, aos quais se atribui a qualidade de gênios criativos por excelência, distanciam-se da maioria da população por possuírem um "dom inato" para criar. Tal concepção baseia-se também na idéia de que criatividade é algo latente, algo que pode "brotar", manifestar-se naturalmente, desde que o meio ofereça condições favoráveis para tanto, como deixar a pessoa livre, deixá-la ser o que ela é.

É importante destacar que essa noção de capacidade criadora como talento inato exclui o fator histórico e social no desenvolvimento da possibilidade de criar, desvinculando a obra criada do contexto de sua produção, considerando-a assim anistoricamente (Zanella, Balbinot e Pereira, 2000).

As respostas de 4 sujeitos, por sua vez, convergiram para a concepção de criatividade enquanto socialmente produzida, tal como apresentada por um dos entrevistados:

\section{“(...)criatividade pode se ensinar (...) acho que é possível dinâmicas de percepção de realidade, é, eu acho que tendo experiências diferentes tu podes ter mais criatividade..." (Sujeito 6).}

Contrapondo-se às respostas das categorias 1 e 3 , a noção de criatividade como um processo socialmente construído estabelece o vínculo entre a atividade criadora e o contexto em que ela se desenvolve, entre o criador e a intrincada trama de relações sociais em que se engendram as significações que ele objetivará em sua obra. Esta, ao ser compartilhada, receberá novos sentidos ${ }^{6}$, a partir da

\footnotetext{
6 A distinção entre significado e sentido é esclarecida por Vygotski (1991, p.333): “(...) o sentido da palavra é a soma
}

leitura dos sujeitos que com ela estabelecerem uma relação estética ${ }^{7}$.

As concepções de criatividade dos acadêmicos no início do semestre letivo encontravam-se, portanto, polarizadas: predominava, em 7 sujeitos, uma perspectiva de natureza humana, sendo que 4 sujeitos apresentaram uma perspectiva que a esta se opõe, na medida em que compreende o psiquismo humano como historicamente produzido.

Após o encerramento das atividades letivas, as quais se fundaram em reflexões teóricas consonantes com a perspectiva apresentada por esses 4 sujeitos nas entrevistas iniciais, os alunos foram novamente entrevistados. Neste segundo momento de coleta de dados, embora a temática tenha sido novamente enfocada através de uma pergunta específica ("O que é criatividade?"), as respostas obtidas foram vagas, o que nos levou a considerar as entrevistas em toda a sua extensão a fim de definir tais concepções. Ainda assim, deparamo-nos com uma concentração de respostas sui generis: 2 dos sujeitos apresentaram uma concepção de criatividade como potencial, pois como já foi ressaltado, remete a uma idéia de natureza humana; 1 demonstrou compartilhar da visão histórico-cultural segundo a qual a criatividade é construída; 1 apresentou respostas que foram categorizadas como híbridas, pois misturam visões inconciliáveis sobre criatividade; e 6 entrevistados apresentaram respostas que manifestam reelaboração do conceito ainda em processo, de modo que não foi possível incluir tais respostas em nenhuma das categorias anteriores.

A concepção de criatividade como potencial foi apresentada por dois (2) sujeitos da seguinte forma:
“(...)criatividade é (...) uma capacidade que todo o mundo tem (...) (Sujeito 1)
“(...)criatividade pra mim é quando a pessoa consegue se expressar da maneira dela (...) consegue não ter tanta influência externa (...)[a disciplina possibilitou] experienciar esse lado, o potencial criativo..." (Sujeito 8).

Tais respostas foram entendidas como inatistas na medida em que nelas são utilizadas expressões que

de todos os eventos psicológicos evocados em nossa consciência graças à palavra. O significado é só uma dessas zonas do sentido, a mais estável, coerente e precisa”.

7 “A relação em que consiste a situação estética se caracteriza pelo papel específico e preeminente que nela desempenha a percepção do objeto pelo sujeito" (Vázquez, 1999, p.135). Através da percepção estética, que o autor caracteriza por um "interesse desinteressado" (p.147), realiza-se a leitura polissêmica do objeto percebido. 
aludem à criatividade enquanto "capacidade que todo o mundo tem", livre das condições históricas e sociais em que se produz, pois lhe é próprio "não ter tanta influência externa", mas ser um "potencial criativo". Importante se faz destacar que esses dois sujeitos apresentaram, na entrevista inicial, respostas semelhantes a essas que foram categorizadas da mesma forma.

A criatividade como produzida socialmente aparece explicitamente na resposta do sujeito 11, o qual já havia apresentado, na primeira entrevista, essa mesma concepção de criatividade:

“(...)criatividade como sendo algo construído socialmente mesmo, a criatividade como sendo algo que não surge do nada, mas que surge exatamente das nossas relações, através ou pelas relações (...)" (Sujeito 11).

A categoria respostas híbridas, por sua vez, foi identificada na fala do sujeito 4, que apresentou, em vários momentos da entrevista, concepções não só diferentes, mas mutuamente excludentes acerca da criatividade. Inicialmente, aparece uma concepção inatista de criatividade:

“(...)a gente viu que todo o mundo tem criatividade (...) todo o mundo mostra de algum jeito (...)" (Sujeito 4).

Contudo, em seguida, a criatividade é definida, por esse mesmo sujeito, de outro modo, remetendo a um processo construído socialmente:

“(...)eu acho que mudou o principal assim que eu achei que era uma coisa da pessoa e aqui eu vi que dá para ser construída e estimulada (...)" (Sujeito 4).

$\mathrm{Na}$ entrevista inicial, a concepção de criatividade apresentada por este sujeito encontrava-se demarcada com maior clareza, tendo sido categorizada como potencial:

“(...)sempre me deixaram muito livre para fazer o que eu quisesse (...)"

Chama a atenção, no entanto, nos resultados da segunda entrevista, o alto índice de respostas que foram categorizadas como "outras": 6 dos 10 sujeitos entrevistados não apresentaram, em suas assertivas, palavras que caracterizassem a opção por uma concepção de criatividade específica tal como anteriormente categorizado. Desses seis sujeitos, na entrevista inicial 3 apresentaram uma concepção de criatividade como potencial (Sujeitos 2, 3, 10), e 3 como construída (Sujeitos 5, 6, 9). Neste segundo momento de coleta de dados, no entanto, suas respostas caracterizaram-se por não apresentarem referências à gênese do processo de criar, o que pode ser exemplificado através dos seguintes trechos:

“(...)criatividade seria (...) tu fazer alguma coisa diferente do que tu faz geralmente no dia-a-dia (...)" (Sujeito 9).

“(...)criatividade (...) eu acho que é a possibilidade de a pessoa inventar, ou criar possibilidades para ela, na vida dela(...)" (Sujeito 3).

“(...)é um modo de ver a vida, de fazer a vida acontecer (...) uma atividade que tá contigo em tudo o que tu vai desempenhar (...) Acho que é criar, criar várias formas de ver e de se expressar (...)" (Sujeito 10).

A retirada do foco de atenção da gênese da criatividade parece indicar um desprendimento daquilo que fomos condicionados a pensar quando se trata deste tema: a vocação, o dom.

$\mathrm{O}$ que nos permite considerar esse conjunto de respostas em uma mesma categoria é, portanto, o fato de que não foi possível identificar palavras que indicassem as respostas que estávamos procurando, tal como apareceu nas entrevistas iniciais. Destaca-se assim que a opção metodológica trouxe alguns problemas neste segundo momento de análise dos dados, pois a pretensão de uma análise do movimento de permanência ou mudança das concepções de criatividade sustentou-se nas categorias de respostas elaboradas a partir das entrevistas iniciais. Ao se manterem essas mesmas categorias de respostas e os mesmos procedimentos para identificá-las - palavras indicadoras das respectivas concepções - revelou-se uma situação ímpar, onde a maioria das respostas das entrevistas finais foi lançada à "caixa preta", ao lugarcomum que metodologicamente abriga os desvios, enfim, aquilo que foge às pretensões nomotéticas dos pesquisadores.

No nosso caso, reconhecemos as dificuldades e limitações que podem advir tanto da própria questão de pesquisa quanto das opções metodológicas adotadas. Os resultados, no entanto, antes que camuflados, precisam ser explicitados, porque, por mais estranhos que pareçam, revelam movimentos, ampliação de sentidos, ressignificações a respeito das concepções de criatividade, que somente uma análise qualitativa pode explicitar. 


\section{UM POSSÍVEL OLHAR SOBRE OS RESULTADOS: SUJEITOS EM PROCESSO DE MUDANÇA}

A análise dos resultados obtidos nos dois momentos da coleta dos dados permite constatar que houve modificações significativas tanto na distribuição quantitativa das respostas quanto na sua qualidade. Quanto à distribuição quantitativa, constatou-se o movimento de permanência e mudança em ambas as categorias de resposta. Dos sete sujeitos que apresentaram, na entrevista inicial, uma concepção de criatividade como inatista (potencial ou todos criativos), dois (sujeitos 1 e 8) mantiveram essa perspectiva após cursarem a disciplina; três deles (sujeitos 2, 3 e 10) tiveram suas respostas categorizadas como "outras respostas"; um (sujeito 4) mudou para híbrida e um (sujeito 7) não participou da segunda entrevista.

Quanto aos quatro sujeitos que apresentaram, na entrevista inicial, concepções consoantes com a trabalhada no decorrer das aulas, constatou-se que, na entrevista final, as respostas de três desses sujeitos (sujeitos 5, 6 e 9) foram categorizadas como "outras respostas" e a de um sujeito (sujeito 11) permaneceu categorizada como construída.

O que essas mudanças indicam? Algumas possíveis respostas podemos apresentar, fundametalmente as que se centram na qualidade das reflexões apresentadas pelos entrevistados. Se num primeiro momento as concepções apontadas pelos sujeitos eram bastante restritas (ou criatividade como potencial, numa concepção inatista, ou criatividade como sendo construída socialmente), observa-se que na entrevista final as respostas apontaram para possibilidades outras de pensar e falar sobre criatividade, que não tinham sido reconhecidas pelos sujeitos anteriormente. Em outras palavras, ainda que a maioria dos sujeitos não tenha apresentado em suas respostas uma palavra ou expressão que remetesse à gênese da criatividade, tais respostas (as que se encontram sob as categorias outras respostas e respostas híbridas), ao abarcarem diversos aspectos da atividade criadora ausentes na entrevista anterior, revelam indícios de processos de mudança.

Tal movimento dos sujeitos reflete-se no seu discurso, como pode ser explicitado através de alguns excertos:

\footnotetext{
"Uma pessoa [é criativa], quando num certo ambiente faz uma coisa diferente para modificar esse ambiente, cria alguma coisa da cabeça dela, específica, e modifica esse ambiente" (sujeito 9, Entrevista Inicial)"
}

“(...)criatividade seria (...) tu fazer alguma coisa diferente do que tu faz geralmente no dia-a-dia (...) fazer a mesma coisa de uma maneira que seja mais gostosa, que chame a atenção, que as pessoas digam 'oh' (...) a gente viu na disciplina, o essencial (...)era tu mudar a tua percepção " (sujeito 9, entrevista final)

“(...)[sou alguém] que tenta estar trazendo a criatividade para a vida, mas não assim (...) nada de muito...de um "dom", né, entre aspas (...) Não acho que eu tenho isso(...)"( sujeito 10 , entrevista inicial).

“(...)[criatividade]é um modo de ver a vida, de fazer a vida acontecer (...) uma atividade que tá contigo em tudo o que tu vai desempenhar (...) Acho que é criar, criar várias formas de ver e de se expressar (...) Agora consegui criar coisas diferentes, (...) é um contato com o que já tá criado para depois tentar recriar (...) tem coisas que antes não me chamavam a atenção e que hoje chamam, eu estou num ambiente, eu estou olhando o que tem aquele ambiente, o que tem de colorido, de arte ali (...)" (sujeito 10, entrevista final).

Observando-se atentamente as respostas desses dois sujeitos, pode-se perceber que nas entrevistas finais, em ambos os casos, a fala sobre criatividade se enriquece, torna-se mais ampla, pois abrange uma multiplicidade de aspectos ausentes na entrevista inicial. O sujeito 9, que inicialmente, para definir quando uma pessoa é criativa, se utilizava de um critério eminentemente comportamental, focalizando apenas o caráter individual e transformador do "produto criativo", num momento posterior acrescenta outras dimensões envolvidas no criar. Além de remeter ao caráter inovador do produto da atividade criadora ('o fazer algo diferente'), enfoca em sua resposta os efeitos desse produto nas pessoas que com ele se relacionam, localizando assim a criatividade numa esfera social. Menciona então que o produto criativo, não obstante modificar um ambiente, é aquele que é fonte de prazer, que impressiona o outro, captando o seu olhar.

Nas respostas do sujeito 10 pode-se igualmente encontrar essa complexificação na concepção de criatividade.Se antes o referido sujeito reconhecia-se como alheio a um suposto "dom" no tocante à criatividade, na entrevista final se reconhece como alguém capaz de criar, de transformar o que já está produzido, imprimindo sua singularidade nos frutos de sua ação criadora. 
É importante destacar que ambos os sujeitos apontam para a mudança de concepção como decorrente do processo vivenciado na disciplina. Isto porque, dentre os conteúdos ali trabalhados, justamente a desautomatização do olhar cotidiano como possibilidade para redimensionar as próprias atividades, retomando o sujeito criador (e não meramente reprodutor), foi debatida em vários momentos, mediada pela contribuição teórica de vários autores.

Este fato indica, por parte dos sujeitos, a apropriação do conceito de percepção estética, que, segundo Vázquez (1999), implica um duplo movimento de distanciamento - em relação a si mesmo e em relação ao objeto - através do qual se resgata o olhar crítico do sujeito. A elaboração deste conceito foi acompanhada, especialmente no sujeito 10, de uma transformação prática ('coisas que agora chamam a atenção nos ambientes onde está').

Por outro lado, na resposta de um dos sujeitos a ampliação da concepção de criatividade, ou seja, sua elaboração segundo olhares que buscassem abarcar o maior número de ângulos acerca do objeto de conhecimento, acabou implicando uma conceituação híbrida:

\begin{abstract}
"(...)a gente viu que todo o mundo tem criatividade (...) todo o mundo mostra de algum jeito(...) eu acho que mudou o principal assim que eu achava que era uma coisa que a pessoa tinha ou não tinha (...) que vinha com a pessoa.(...) eu achava que eu não tinha, porque eu nunca ia ser criativa e que não adiantava e aqui nas aulas, quando há estímulos, quando a gente é exposto a determinado estímulo (...) aqui eu vi que a criatividade dá pra ser construída" (sujeito 4, entrevista final).
\end{abstract}

Esta resposta contempla duas concepções de criatividade claramente antagônicas, sendo justamente por este fato caracterizada como híbrida. Indica as dificuldades desse sujeito em estabelecer distinções entre diferentes concepções teóricas, o que o leva a utilizar ambas como se pudessem significar de modo semelhante aquilo a que se referem, neste caso, a criatividade.

$\mathrm{Se}$ as mudanças quantitativas são visíveis nos números apresentados, afirmar a presença de mudanças qualitativas requer uma volta às falas dos sujeitos.

"Eu sabia intuitivamente o que era criatividade (...) quando a gente foi fazendo as oficinas, de pintura, capoeira, esculturinha de papel, etc, depois a gente refletia sobre o trabalho (...) antes também eu pensava criatividade diretamente como arte (...) agora eu torno mais amplo" (sujeito 6, entrevista final).

Nessa fala, o sujeito 6 afirma reconhecer o próprio processo de transformação nele engendrado pela participação na disciplina: se antes compreendia a criatividade a partir da própria atividade criadora ${ }^{8}$, o contexto da disciplina abriu-lhe possibilidades para distanciar-se de sua prática, refletindo sobre ela com a mediação das discussões teóricas engendradas no contexto da sala de aula. Desse modo, ao estabelecer uma relação com a criatividade via pensamento em conceitos (Vygotski, 1996), superou a imediaticidade do vivencial, (re) significando-a numa esfera consciente, pautada, portanto, por processos psicológicos superiores. Ao 'retornar' para a própria experiência, foi capaz ainda de perceber que a criatividade envolve muitas outras esferas de ação humana além da arte, o que também foi debatido no contexto da disciplina.

\section{CONSIDERAÇÕES FINAIS}

Os resultados da pesquisa realizada permitem afirmar que houve modificações nas concepções de criatividade dos acadêmicos de psicologia investigados, ainda que para três deles a gênese do criar tenha se mantido nos dois momentos da coleta de dados. As modificações referidas, para alguns (sujeitos 9, 10 e 4), consistiram na ampliação das possibilidades de referirem-se à atividade criadora e seus produtos. Para outros (sujeitos 6 e 11) a mudança, além de se dar neste nível mais próximo da experiência prática, engendrou complexas redes de conceitos interligados. Destaca-se, portanto, que as reflexões engendradas bem como as vivências estéticas naquele contexto foram significativas no sentido de que possibilitaram, aos sujeitos envolvidos, ressignificarem concepções ou práticas, o que se objetivou na complexificação das respostas apresentadas.

Esses resultados permitem afirmar que constituir um contexto formal de ensinar e aprender pautado por uma abordagem que busca estabelecer inter-relações entre discussões teóricas e oficinas estéticas, é fundamental para a ressignificação das concepções sobre criatividade. Porém, não há garantias de que todos os sujeitos passem a utilizar a perspectiva

\footnotetext{
${ }^{8} \mathrm{O}$ sujeito em questão dedica-se a diversas atividades artísticas.
} 
teórica trabalhada para se referirem à temática em questão, o que aconteceu com os sujeitos 1 e 8 . A que se deve isso?

Respostas a essa pergunta podem ser obtidas por duas vias: através de novas entrevistas com esses sujeitos, que busquem investigar aspectos variados, como escolhas teóricas, percepção das diferenças entre concepções sobre a temática, processos de identificação (ou não) com professores ou referenciais teóricos. Outra opção seria buscar esses indicativos via análise do processo de ensinar e aprender, onde participação, contraposição, adesão, negação pudessem ser observadas. Mas isso já é outro trabalho, que, embora nos mobilize, foge ao escopo do que é possível, neste momento, responder.

\section{REFERÊNCIAS}

Franco, M. L. P. B. (1994) Ensino médio: desafios e reflexões. Campinas: Papirus.

Pino, A. (1995) Semiótica e cognição na perspectiva históricocultural. Temas em Psicologia, 2, 31-40.

Triviños, A. N. S. (1987) Introdução à pesquisa em ciências sociais: a Pesquisa Qualitativa em Educação. São Paulo: Atlas.

Vázquez, A. S. (1999) Convite à estética. Rio de Janeiro: Civilização Brasileira.

Vygotski, L. S. (1987) História del desarollo de las funciones psíquicas superiores. La Habana/Cuba: Ed. CientíficoTécnica

Vigotskii, L. S. (1990) La imaginacion y el arte en la infancia. Madrid: Akal.

Vigotski, L. S. (1991) Obras Escogidas III: problemas del desarollo de la psique. Madrid: Visor Distribuiciones.

Vygotsky, L. S. (1996) Teoria e método em psicologia. São Paulo: Martins Fontes.

Zanella, A. V., Balbinot, G., Pereira, R. S. (2000) Re-criar a (na) renda de bilro: analisando a nova trama tecida. Psicologia: Reflexão e Crítica. 3,13,539-547.

Recebido em 20/08/2002

Revisado em 12/12/2002

Aceito em 30/05/2003 